University of Nebraska - Lincoln

DigitalCommons@University of Nebraska - Lincoln

USDA Wildlife Services - Staff Publications

U.S. Department of Agriculture: Animal and Plant Health Inspection Service

February 2007

\title{
A Frightening Device for Deterring Deer Use of Cattle Feeders
}

\author{
Nathan W. Seward \\ United States Department of Agriculture, Animal and Plant Health Inspection Service, Wildlife Services, \\ National Wildlife Research Center \\ Gregory E. Phillips \\ United States Department of Agriculture, Animal and Plant Health Inspection Service, Wildlife Services, \\ National Wildlife Research Center \\ Jared F. Duquette \\ United States Department of Agriculture, Animal and Plant Health Inspection Service, Wildlife Services, \\ National Wildlife Research Center \\ Kurt C. Vercauteren \\ USDA-APHIS-Wildlife Services, kurt.c.vercauteren@usda.gov
}

Follow this and additional works at: https://digitalcommons.unl.edu/icwdm_usdanwrc

Part of the Environmental Sciences Commons

Seward, Nathan W.; Phillips, Gregory E.; Duquette, Jared F.; and Vercauteren, Kurt C., "A Frightening Device for Deterring Deer Use of Cattle Feeders" (2007). USDA Wildlife Services - Staff Publications. 654.

https://digitalcommons.unl.edu/icwdm_usdanwrc/654

This Article is brought to you for free and open access by the U.S. Department of Agriculture: Animal and Plant Health Inspection Service at DigitalCommons@University of Nebraska - Lincoln. It has been accepted for inclusion in USDA Wildlife Services - Staff Publications by an authorized administrator of DigitalCommons@University of Nebraska - Lincoln. 


\section{A Frightening Device for Deterring Deer Use of Cattle Feeders}

NATHAN W. SEWARD, United States Department of Agriculture, Animal and Plant Health Inspection Service, Wildlife Services, National Wildife Research Center, 4101 LaPorte Avenue, Fort Collins, CO 80521, USA

GREGORY E. PHILLIPS, United States Department of Agriculture, Animal and Plant Health Inspection Service, Wildlife Services, National Wildlife Research Center, 4101 LaPorte Avenue, Fort Collins, CO 80521, USA

JARED F. DUQUETTE, ${ }^{\mathbf{1}}$ United States Department of Agriculture, Animal and Plant Health Inspection Service, Wildlife Services, National Wildife Research Center, 4101 LaPorte Avenue, Fort Collins, CO 80521, USA

KURT C. VERCAUTEREN, ${ }^{2}$ United States Department of Agriculture, Animal and Plant Health Inspection Service, Wildlife Services, National Wildife Research Center, 4101 LaPorte Avenue, Fort Collins, CO 80521, USA

?1 ABSTRACT The presence of bovine tuberculosis (TB) in cattle can negatively impact a state's economy and cattle industry. In Michigan, USA, wild white-tailed deer (Odocoileus virginianus) are a reservoir for reinfecting cattle herds. Although direct TB transmission between deer and cattle is rare, infected deer may contaminate cattle feed. To mitigate this risk, we designed and evaluated a deer-resistant cattle feeder (DRCF) device for deterring deer from feeders. The device delivered negative stimuli to condition deer to avoid cattle feeders. We tested the device by conducting a comparative change experiment at a high-density captive white-tailed deer operation in northeastern lower Michigan using pretreatment and treatment periods and random allocation of DRCF protection to 3 of 6 feeders during the treatment period. We used animal-activated cameras to collect data on deer use of feeders. Deer use was similar at protected and unprotected feeders during the pretreatment period but was lower at protected feeders during the treatment period. Deer-resistant cattle feeders were 100\% effective during the first 2 treatment weeks, $94 \%$ during the first 5 weeks, but effectiveness then dropped to $61 \%$ during the final week. Excluding problems associated with low battery power and infrared sensors, DRCFs were $99 \%$ effective at deterring deer. Our results suggest that DRCFs can effectively limit deer use of cattle feed, potentially with minimal impact on feeding behavior of cattle, thus reducing potential transmission of bovine TB through contaminated feed. By employing DRCFs in bovine TB endemic areas, especially at times that deer are food stressed, agencies and producers can practically and economically reduce the potential for bovine TB to be transmitted from deer to cattle. (JOURNAL OF WILDLIFE MANAGEMENT 71(1):271-276; 2007)

DOI: $10.2193 .2006-265$

KEY WORDS bovine tuberculosis, cattle, deer-resistant cattle feeder, disease transmission, feeding, frightening device, Michigan, Mycobacterium bovis, Odocoileus virginianus.

In 1917 the United States Department of Agriculture established the goal of eradicating bovine tuberculosis (TB) from the United States because of concerns to human health and negative impacts on the livestock industry (Schmitt et al. 1997). Though quite successful, sporadic outbreaks are occasionally identified in cattle populations. Between 1998 and 2003, Michigan, USA, lost an estimated US\$22-74 million after losing accredited TB-free status, which is required to transport cattle interstate (United States Department of Agriculture 2000). White-tailed deer (Odocoileus virginianus) harvested by hunters have been used to verify that bovine $\mathrm{TB}$ is present in deer in northeastern lower Michigan (Schmitt et al. 1997, Hickling 2002). Deer likely contracted the disease from infected cattle and now act as the main reservoir for reinfecting cattle herds in Michigan (Davidson and Nettles 1997).

Bovine TB can be transmitted through shared feed (Palmer et al. 2001, 2004), putting cattle that consume contaminated feed at risk. Management strategies to reduce TB transmission among deer and between deer and cattle have included increasing hunter harvest to reduce deer densities, restricting baiting and feeding, culling, fencing stored feed, depopulating infected cattle and captive cervid

\footnotetext{
1 Present address: The Obio State University, School of Natural Resources, 2021 Coffey Road, Columbus, OH 43210, USA

2 E-mail: kurt.c.vercauteren@aphis.usda.gov
}

farms, and conducting research on nonlethal means to reduce transmission to cattle (e.g., frightening devices, dogs, fencing). These efforts appear to have reduced the prevalence in deer over the past 8 years to an estimated $1.7 \%$ (O’Brien et al. 2006). Regardless, bovine TB is likely to persist in northeastern lower Michigan for $>10$ years (O’Brien et al. 2006), and producers need tools to protect their herds.

Various repellents and nonlethal frightening devices exist for deterring deer, but these methods are typically ineffective (Wagner and Nolte 2001; Gilsdorf et al. 2002; VerCauteren et al. 2006a, b). Excluding electricity, we found no studies evaluating physical stimuli for deterring deer. Nolte et al. (2003) conditioned deer to avoid food plots using electric shock collars but concluded the application was impractical due to technological limitations and cost. Nonetheless, negative physical stimuli have potential for conditioning deer and providing effective means for producers to alleviate damage and deer use of cattle resources.

Husbandry and sanitation practices that reduce feed contamination and potential disease transmission would aid Michigan's cattle industry in regaining accredited TBfree status. We addressed an aspect of this need by designing and evaluating an animal-activated frightening device to protect cattle feed that stimulated a deer's sense of sight, hearing, and touch. Through negative physical stimuli, we 


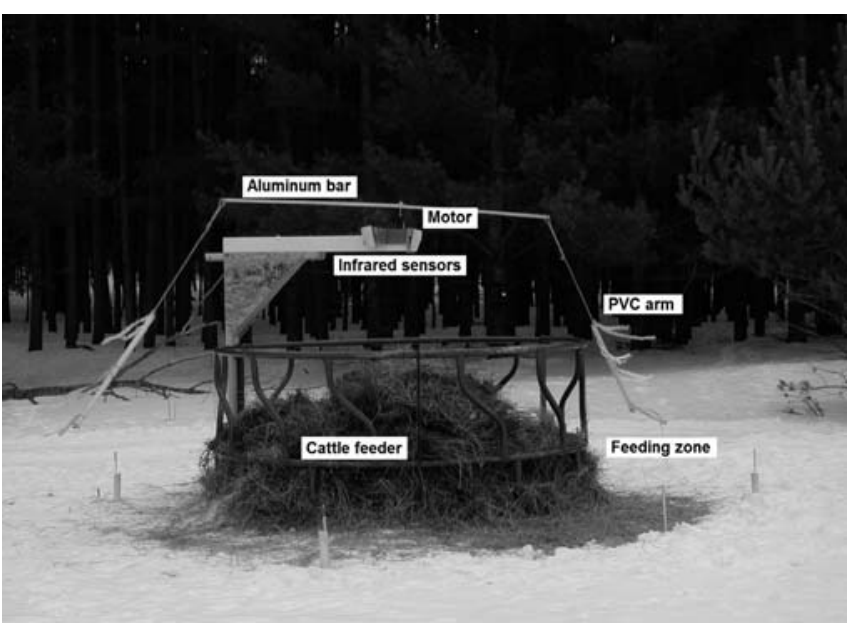

Figure 1. Deer-resistant cattle feeder with white fiberglass posts and reflective tape marking the $1-\mathrm{m}$ wide feeding zone. (PVC indicates polyvinyl chloride)

intended to deter deer from cattle feeders. Our primary objectives were to 1) design an economical frightening device to physically deter deer from using cattle feed, 2) evaluate its efficacy under an artificially high deer density, and 3) assess its durability and effect on cattle.

\section{STUDY AREA}

We conducted the study on 2 farms in Montmorency County in northeastern lower Michigan $\left(45^{\circ} 01^{\prime} \mathrm{N}\right.$, $\left.84^{\circ} 07^{\prime} \mathrm{W}\right)$. We initially evaluated our deer-resistant cattle feeder (DRCF) on a privately owned 34.2-ha enclosure containing 105 white-tailed deer $\left(307 \mathrm{deer} / \mathrm{km}^{2}\right)$. For comparison, density of free-ranging deer in the region (DMU452) was 19-23 deer $/ \mathrm{km}^{2}$ at the outset of the bovine TB epidemic (Schmitt et al. 1997, Palmer et al. 2001). Little natural vegetation was available for deer in the enclosure, as indicated by a browse-line throughout the understory. Vegetation in the enclosure consisted of approximately $90 \%$ forest and $10 \%$ herbaceous openings (e.g., grassland). We conducted the second phase of the study on a 50-ha cattle farm with 35 cattle to assess the utility of DRCFs. We rotated cattle among 10 5-ha grassland pastures. We commonly observed white-tailed deer along the pasturehardwood forest interface surrounding the farm.

\section{METHODS}

\section{Frightening Device Design}

We designed the DRCF to deliver a negative physical stimulus when deer attempted to feed from cattle feeders (Fig. 1). We constructed the DRCF by using an 18-gauge high-tensile tubing round-bale feeder (HW Brand, Hutchison, Inc., Adams City, CO) as the frame to suspend a wooden platform and cabinet that housed the electronics and gearmotor (Dayton Electric Manufacturing Co., Niles, IL). Electronics in the cabinet included main relay, timer, and a $12-\mathrm{V}$ lead-acid battery that powered 3 weatherproof passive infrared (IR) sensors (model LX-402; Optex Inc., Torrance, CA), which activated the DRCF. We mounted 3 IR sensors with a $120^{\circ}$ field of view (FOV) from the center of the feeder to detect animals approaching from any direction. We adjusted the photocell in each IR sensor to control activation under various ambient light conditions and restricted the distance IR sensors could detect by angling the sensors downward approximately $45^{\circ}$, creating a 5-m surveillance zone around the feeder. Animals activated the DRCF when they penetrated the surveillance zone and triggered an IR sensor. When an IR sensor was triggered, the main relay activated an electronic timer that limited gearmotor rotation to approximately 45 seconds. The gearmotor revolved at 30 rotations per minute with a load torque of $29.3 \mathrm{kgf} / \mathrm{m}$. The gearmotor rotated a $3.4-\mathrm{m}$ aluminum bar with $21.6-\mathrm{m}$-long polyvinyl chloride (PVC) conduit arms that hung down from steel chains to $45 \mathrm{~cm}$ above the ground. Animals would be struck by the arms if they attempted to feed ( $\leq 1 \mathrm{~m}$ from the feeder). We designed force of impact to startle deer, not hurt them, and it was not perceived painful by humans. In addition to physical stimulus, revolving arms provided visual and auditory stimulation. After each 45-second activation, the 3 IR sensors had to reset (i.e., not detect movement and body heat for $2 \mathrm{sec}$ ) before the DRCF could be reactivated. We used 2 deep-cycle $12-\mathrm{V}$ batteries on the ground inside the feeder to power the DRCF. The National Wildlife Research Center's Animal Care and Use Committee approved the study (QA-1257).

\section{Deer Trial}

We installed cattle feeders at 6 feeding sites well distributed within the deer enclosure. We randomly assigned different treatments to each feeder (protected using DRCF and unprotected without DRCF). We separated feeders by $\geq 160 \mathrm{~m}$ and maintained them with $454-\mathrm{kg}$ round bales of alfalfa fodder and $2.2 \mathrm{~kg}$ of whole-kernel corn scattered on top. We provided feed at only these 6 sites.

We used Reconyx ${ }^{\circledR}$ Silent Image ${ }^{\mathrm{TM}}$ digital cameras (Reconyx, LLP, La Crosse, WI) to capture presence and behavior of deer at feeders. We installed 2 cameras at diametrically opposing locations $10.2 \mathrm{~m}$ from the center of each feeder (Fig. 2). Cameras were triggered when IR sensors detected movement and body heat of an animal. Each camera trigger resulted in a series of 99 pictures with 2 seconds between pictures (i.e., camera event), recording approximately 5 minutes of staggered footage.

We defined a sampling zone for each camera based on the camera's FOV out to the center of the feeder (Fig. 2). Deer inside the sampling zone were well illuminated and easily distinguishable. Deer beyond that distance (outside the sampling zone) were not easily distinguishable during darkness, with some deer hidden behind the feeder. We did not count deer outside of the sampling zone until they entered. Within the sampling zone we defined a feeding zone, a 1-m swath around the feeder (Fig. 2). We marked the perimeter of the feeding zone with $81.0-\mathrm{cm}$-diameter fiberglass posts and reflective tape (Fig. 1) to easily determine when deer breached the feeding zone. We classified deer that breached the feeding zone as having fed successfully, even if they did not directly contact feed. 


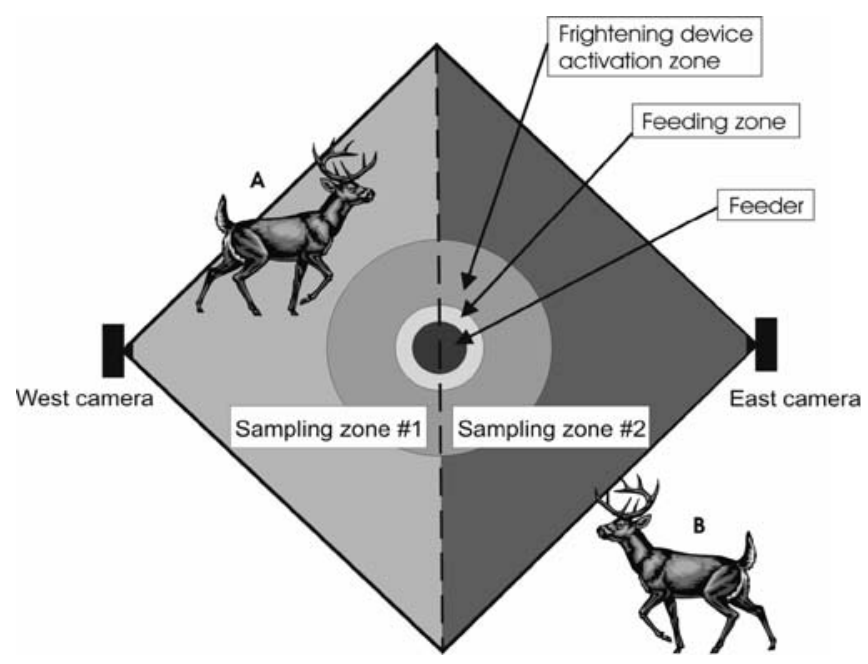

Figure 2. Camera sampling zones and the 5-m wide activation zone of the frightening device relative to the cattle feeder and 1-m wide feeding zone, northeastern lower Michigan, USA, 2005. Researchers reduced visual error associated with counting deer during night by including only deer in the sampling zone closest to the camera. For a count from the west camera, we would only include deer A, even though deer B is likely visible in the background. We would not count deer B because the deer is outside of sampling zone \#1 (light gray area). However for a count the following day from the east camera, we would count deer B after it entered sampling zone \#2 (dark gray area), whereas we would exclude deer A.

We adopted a liberal definition of successful feeding because infected deer may be capable of contaminating feed with Mycobacterium bovis through respiratory aerosols at this distance.

We monitored deer use of feeders continuously during a 4week pretreatment period (10 Feb-10 Mar) before installing $\mathrm{DRCFs}$ at feeders assigned to the protected group. We monitored early versions of DRCFs and upgraded components for improved performance during a developmental period (13 Mar-4 May), and conducted tests of final prototypes during a treatment period (13 May-23 Jun). We checked DRCFs daily to ensure proper functioning and refilled feeders with fodder and corn as needed to maintain attractiveness.

\section{Cattle Trial}

Following the deer trial, we conducted a cursory evaluation at a cattle farm to determine whether DRCFs would affect cattle behavior and to assess their durability (13 Jul-12 Aug). A DRCF was always present, as cattle were rotated among pastures. To simulate how DRCFs might be used in service, we calibrated IR sensors to activate the DRCF only at night, allowing cattle to feed during the day without disturbance but operant to deter deer at night. Cattle attempting to feed at night would also trigger the DRCF, potentially inhibiting them from feeding. Cameras monitored DRCFs exactly as during the deer trial. We quantified the number of camera events triggered by cattle, number of cattle feeding per camera event, cattle response to the DRCF, and DRCF malfunctions. We maintained cameras and refilled the DRCF-protected feeder with 454-kg bales of fodder every other day.

\section{Statistical Analysis}

Deer trial.-We analyzed data from the pretreatment period and the final prototype treatment period. We subsampled camera events before quantifying response variables for analyses to reduce the data set. We used data from only one camera per feeder per day. After randomly selecting the initial camera to observe each week, we alternated opposing cameras between successive days of the week. If a camera malfunctioned or had poor image quality (e.g., fogged lens), we substituted contemporaneous data from the opposing camera. To reduce serial correlation between successive camera events (e.g., double-counting), we excluded data obtained within 60 minutes of a sampled camera event.

We reviewed all images in each selected camera event and quantified 2 response variables based on count data per camera event: total number of deer within the sampling zone $\left(T_{\mathrm{S}}\right)$ and total number of deer within the feeding zone $\left(T_{\mathrm{F}}\right)$. We counted total number of deer in the sampling zone in the first frame and added additional deer as they entered the sampling zone during the sequence of 99 pictures. We could not identify individuals, so double-counting of deer may have occurred if an individual left the sampling zone and reentered during the same camera event. We did not double-count deer that breached the feeding zone if they left the feeding zone, remained within the FOV, and reentered the feeding zone during the same camera event. However, we would have double-counted deer if they left the FOV and reentered the feeding zone.

We used a third response variable to estimate deterrence rate $(d)$ for DRCFs during the deer trial. While reviewing subsampled camera events, we observed deer movements toward feeders and outcomes relative to feeding success. We opportunistically considered any occasion when a deer entered the sampling zone and moved toward a protected feeder as a Bernoulli trial with the outcomes either failure (0: deer penetrated the feeding zone) or success (1: deer was deterred from entering the feeding zone). We did not consider occasions where the camera event ended before a definitive outcome was observed or cases when deer were already inside the feeding zone when a camera event began.

We estimated mean $T_{\mathrm{S}}\left(\bar{T}_{\mathrm{S}}\right)$, mean $T_{\mathrm{F}}\left(\bar{T}_{\mathrm{F}}\right)$, and $d$ by week to evaluate efficacy of the DRCF over time. We used generalized estimating equations (Liang and Zeger 1986, Zeger and Liang 1986) with an autoregressive correlation structure in the GENMOD procedure of SAS (SAS Version 9.1; SAS Institute, Cary, NC) to account for repeated measures within sites. We based inferences on model-based standard errors to address small sample sizes $\left(n=6\right.$ for $\bar{T}_{\mathrm{S}}$ and $\bar{T}_{\mathrm{F}}$, and $n=3$ for $d$; Prentice 1988, SAS Institute 2005).

We modeled $\bar{T}_{\mathrm{S}}$ and $\bar{T}_{\mathrm{F}}$ separately for pretreatment and treatment periods (because these time periods differed) using a model structure consisting of treatment group, week within period, and interaction. We used the negative binomial distribution with a $\log$ link to explicitly account for overdispersion in the count data. Our sampling and subsampling protocols resulted in different sample sizes of 


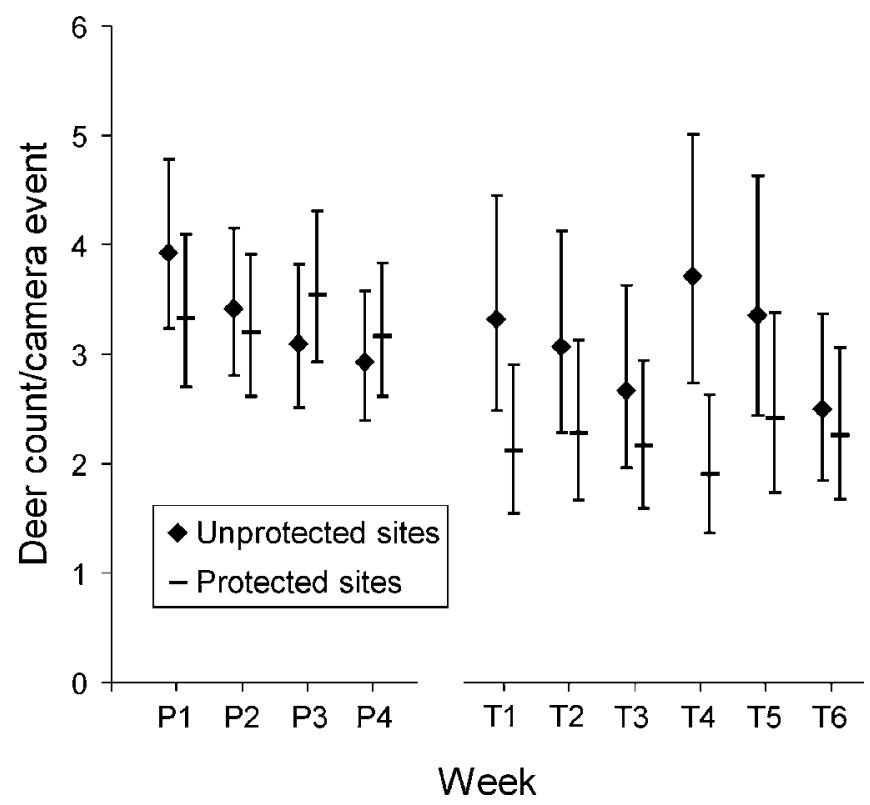

Figure 3. Mean number of deer counted per camera event within the overall sampling zone around cattle feeders at 3 unprotected sites and 3 sites protected by deer-resistant cattle feeders in northeastern lower Michigan, USA, 2005. The pretreatment period extended from 10 February to 9 March (weeks P1-P4) and treatment period extended from 13 May to 23 June (weeks T1-T6). Error bars represent 95\% confidence intervals.

camera events among cameras and weeks, so we used weekly sample size for each camera as an offset variable to estimate $\bar{T}_{\mathrm{S}}$ and $\bar{T}_{\mathrm{F}}$. We used logistic regression (Hosmer and Lemeshow 1989) to estimate $d$ (deterrence rate = weekly no. of deer repelled/weekly no. of deer attempting to feed) at protected feeders within the 6-week treatment period.

Cattle trial.-We used chi-square goodness-of-fit methods (PROC FREQ; SAS Institute) to estimate various proportions $(p)$ involving camera events. We reported Wald 95\% confidence intervals for large samples and exact intervals for small samples, and we used interval overlap to compare proportions.

\section{RESULTS}

\section{Deer Trial}

Subsampling from our data set produced 2,386 camera events with 999 from the pretreatment period (472 at unprotected feeders and 527 at protected feeders) and 1,387 from the treatment period (698 at unprotected feeders and 689 at protected feeders). Weekly sample size per feeder ranged from 17 to 58 and 13 to 79 for unprotected and protected feeders, respectively, during the pretreatment period, and from 12 to 69 and 12 to 78 for unprotected and protected feeders, respectively, during the treatment period.

Mean numbers of deer counted within the sampling zone at feeders $\left(\bar{T}_{\mathrm{S}}\right)$ were clearly similar for unprotected and protected sites during the pretreatment period (Fig. 3). There was some indication of deterrence at protected feeders during the treatment period, but statistical difference was evident only during week T4 (Fig. 3). During the pretreatment period, weekly estimates of $\bar{T}_{\mathrm{F}}$ were approximately equal at unprotected and protected sites, but during the treatment period we observed fewer deer within feeding zones protected by DRCFs (Fig. 4). We observed no deer within $1 \mathrm{~m}$ of protected feeders during the first 2 treatment weeks, but deer intrusions gradually increased to an average of about 0.4 deer per camera event by the final treatment week. Average numbers of deer per camera event at protected and unprotected sites were statistically indistinguishable in the final treatment week.

We documented 323 cases when deer attempted to feed at DRCFs that resulted in a definitive binary outcome (entered feeding zone vs. deterred by DRCF). Weekly sample size ranged from 28 to 119 (Fig. 5). We recorded no successful entry into feeding zones $(d=1.0)$ during the first 2 treatment weeks, and $d$ ranged from 0.91 to 0.94 during weeks 3-5 (Fig. 5). On average, $d=0.94$ (95\% CI: 0.860.97 ) during the first 5 weeks of the treatment period, but dropped to 0.61 (95\% CI: 0.48-0.74) during the final week of the treatment period.

\section{Cattle Trial}

We acquired 543 camera events triggered by cattle, of which 354 occurred during daytime $(P=0.65,95 \%$ CI: $0.61-$ $0.69)$. This was consistent with equal activity per unit time throughout the diel period at the place and time of our study (approx. $16 \mathrm{hr}$ of daylight constituting 67\% of the diel period). During daylight, 309 camera events $(P=0.87,95 \%$ CI: 0.84-0.91) showed cattle feeding and 45 showed cattle passing by without attempting to feed. At night, we observed cattle feeding during 108 of 189 camera events, cattle did not attempt to feed during 60 camera events, and cattle were deterred from feeding by the DRCF during 21 camera events. Cattle fed undeterred during 19 of 40 camera

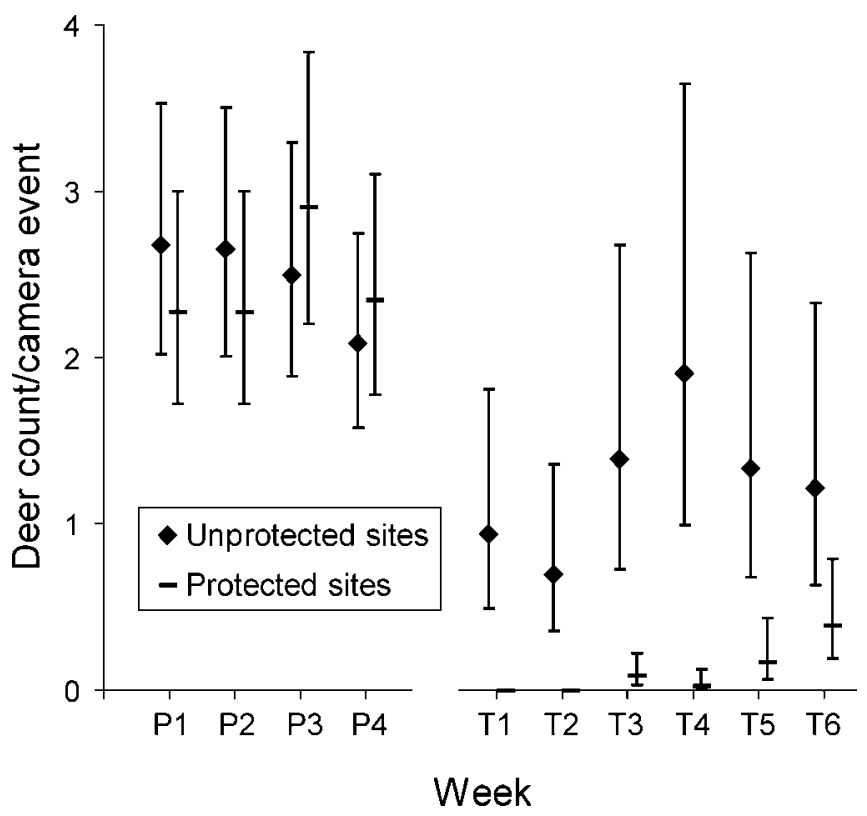

Figure 4. Mean number of deer counted per camera event within the feeding zone $\leq 1 \mathrm{~m}$ from feeder at 3 unprotected sites and 3 sites protected by deer-resistant cattle feeders in northeastern lower Michigan, USA, 2005. The pretreatment period extended from 10 February to 9 March (weeks P1-P4) and treatment period extended from 13 May to 23 June (weeks T1T6). Error bars represent $95 \%$ confidence intervals. 


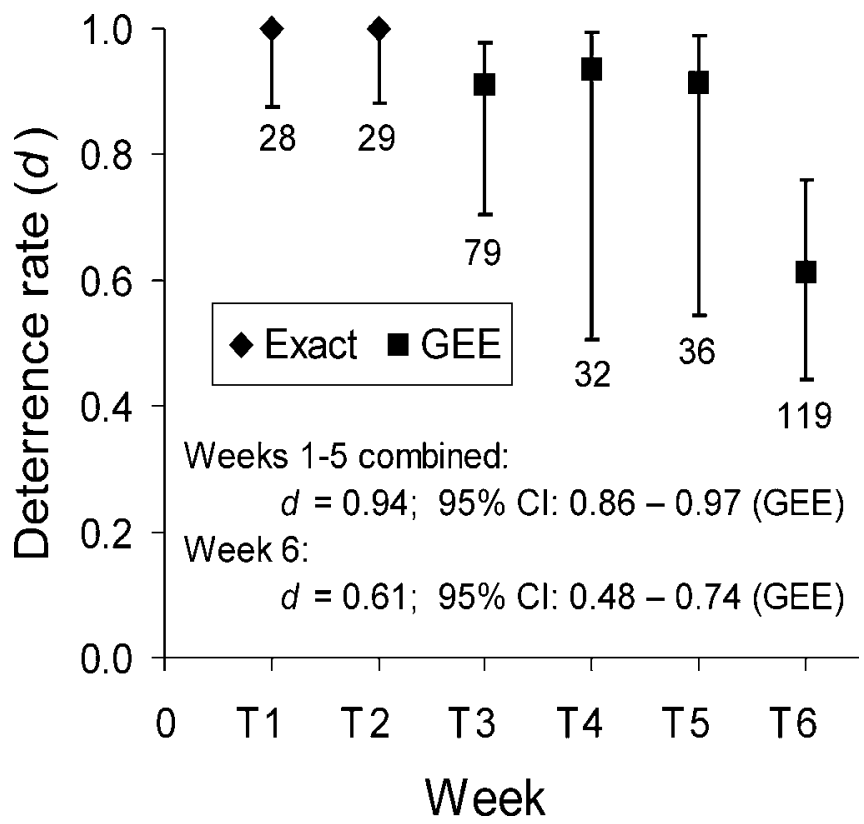

Figure 5. Estimated feeding-deterrence rate $(d)$ for deer attempting to feed from round-bale feeders protected by deer-resistant cattle feeders in northeastern lower Michigan, USA, 2005. Sample size (trials) shown below error bars (95\% CIs). We give Fisher's exact confidence intervals for weeks T1 and T2 (where $d=1.0$ ), whereas we based those for weeks T3-T6 on model-based standard errors from generalized estimating equations (GEE).

events $(P=0.48,95 \%$ CI: $0.32-0.63)$ when the DRCF was known to be functional during darkness; this was a significantly lower rate than during daylight. During the first week of the cattle trial, only $29 \%$ of DRCF-functional camera events showed cattle feeding $(P=0.29$, exact $95 \%$ CI: 0.04-0.71), but that rate increased in following weeks to $75 \%$ by the final (fourth) week of the trial $(P=0.75$, exact 95\% CI: 0.19-0.99). Because of low weekly sample sizes, this apparent change was statistically indistinguishable.

The DRCF was nonfunctional during $\geq 119$ of 189 nighttime camera events because of sensor or battery malfunction (76 events), hanging PVC arm caught in feeder (24 events), or broken support arm or hanging PVC arms (19 events). We found the DRCF nonfunctional at maintenance checks 17 of 30 days.

\section{DISCUSSION}

Deer were highly motivated to use the feeders because deer densities were very high and little natural food was available at our study site. During the developmental phase, deer learned to feed successfully by taking advantage of design flaws that caused DRCFs to malfunction. They initially fled after entering the detection zone of IR sensors and activating the DRCF but began to habituate to the activation of DRCFs. We observed deer standing slightly out of reach of the revolving PVC arms and also skirting the detection zone of IR sensors to avoid activating DRCFs. During the treatment phase of our final prototype, residual design flaws continued to cause DRCFs to malfunction. However, only one deer defeated the DRCF when it was operating properly. Excluding deer that penetrated the feeding zone due to low battery power (for the motor) and problems associated with the resetting of IR sensors, DRCFs were $>99 \%$ effective at deterring deer from accessing protected feeders. Unlike cows, deer were not willing to be struck by the PVC arms of the DRCF.

High activation rates and the inability of IR sensors to immediately reset after being activated caused malfunctions that allowed deer to feed. The inability of IR sensors to reset and reactivate the DRCF because of the continued detection of animal movement (e.g., large no. of deer approaching the feeder) was a flaw that deer learned to exploit over time. Groups of habituated deer triggered the DRCF, stood slightly out of reach of the revolving arms, and then penetrated the feeding zone as sensors were unable to reset. Once all deer in the detection zone stopped moving, however, sensors could reset and reactivate the DRCF, which always frightened deer out of the feeding zone. Deer attempted to feed repeatedly, which depleted battery power to the point of DRCFs being inoperative. Additionally, other species such as wild turkey (Meleagris gallopovo), raccoon (Procyon lotor), red squirrel (Tamiasciurus hudsonicus), and gray squirrel (Sciurus carolinensis) also activated DRCFs, which drained battery power.

Problems associated with low battery power and IR sensors would occur less frequently in real-world situations under lower free-ranging deer densities and greater abundance of natural browse. However, a redesigned sensor system (to enable immediate retriggering if animals remain inside the detection zone) and an improved power supply may facilitate reliable DRCF performance in the presence of deer and cattle. Additionally, round-bale feeders should be firmly anchored in the ground to prevent cattle from moving and potentially disconnecting the battery power supply should deep-cycle $12-\mathrm{V}$ batteries continue to be used. Aluminum support arms and hanging PVC arms may need to be strengthened or otherwise modified to prevent breakage and jamming by cattle.

Our results suggest that cattle are as active around feeders during darkness as during daylight and that DRCFs may initially deter cattle. Evidence suggests that cattle were adjusting to DRCFs; however, our sample was too small to conclusively prove acclimation. General acceptance of DRCFs by cattle producers will likely require further evidence that these devices do not have negative effects. Cost per unit was US $\$ 750$, excluding the round-bale feeder, making DRCFs an affordable addition to a producer's integrated biosecurity plan.

\section{MANAGEMENT IMPLICATIONS}

Bovine TB is a chronic problem plaguing cattle producers in northeastern lower Michigan. Cattle producers in the region should take an active role in protecting their herds and need more practical and cost-effective methods to do so. The DRCF is an example of the United States Department of Agriculture's effort to provide tools to producers. Even under the extreme conditions of our test, DRCFs successfully deterred deer from using cattle feed for the 6-week 
treatment period. With modification of IR sensors, hanging arms, and the power supply, DRCFs could repel freeranging deer indefinitely and be practical enough to be used by producers.

\section{ACKNOWLEDGMENTS}

We thank J. Fischer, M. Lavelle, and M. Pierce for their help during construction and initial testing of the frightening device. We thank the landowners for access to their properties and M. Dunbar for reviewing an earlier draft of the manuscript.

\section{LITERATURE CITED}

Davidson, W. R., and V. F. Nettles. 1997. Field manual of wildlife diseases in the southeastern United States. Second edition. Southeastern Cooperative Wildlife Disease Study, Athens, Georgia, USA.

Gilsdorf, J. M., S. E. Hygnstrom, and K. C. VerCauteren. 2002. Use of frightening devices in wildlife management. Integrated Pest Management Reviews 7:29-45.

Hickling, G. J. 2002. Dynamics of bovine tuberculosis in wild white-tailed deer in Michigan. Michigan Department of Natural Resources Wildlife Division Report 3363, Lansing, USA.

Hosmer, D. W., Jr., and S. Lemeshow. 1989. Applied logistic regression. John Wiley, New York, New York, USA.

Liang, K. Y., and S. L. Zeger. 1986. Longitudinal data analysis using generalized linear models. Biometrika 73:13-22.

Nolte, D. L., K. C. VerCauteren, K. R. Perry, and S. E. Adams. 2003. Training deer to avoid sites through negative reinforcement. Proceedings of the Wildlife Damage Management Conference 10:95-104.

O’Brien, D. J., S. M. Schmitt, S. D. Fitzgerald, D. E. Berry, and G. J.
Hickling. 2006. Managing the wildlife reservoir of Mycobacterium bovis: the Michigan, USA, experience. Veterinary Microbiology 112:313-323.

Palmer, M. V., W. R. Waters, and D. L. Whipple. 2004. Shared feed as a means of deer-to-deer transmission of Mycobacterium bovis. Journal of Wildlife Diseases 40:87-91.

Palmer, M. V., D. L. Whipple, and R. Waters. 2001. Experimental deerto-deer transmission of Mycobacterium bovis. American Journal of Veterinary Research 62:692-696.

Prentice, R. L. 1988. Correlated binary regression with covariates specific to each binary observation. Biometrics 44:1033-1048.

SAS Institute. 2005. GEE analyses using the GENMOD procedure course notes. SAS Institute, Cary, North Carolina, USA.

Schmitt, S. M., S. D. Fitzgerald, T. M. Cooley, C. S. Bruning-Fann, L. Sullivan, D. Berry, T. Carlson, R. B. Minnis, J. B. Payeur, and J. Sikarskie. 1997. Bovine tuberculosis in free-ranging white-tailed deer from Michigan. Journal of Wildlife Diseases 33:749-758.

United States Department of Agriculture. 2000. The comprehensive strategic plan for the eradication of bovine tuberculosis. United States Department of Agriculture, Animal and Plant Health Inspection Service, Veterinary Services, Washington, D.C., USA.

VerCauteren, K. C., J. M. Gilsdorf, S. E. Hygnstrom, P. B. Fioranelli, J. A. Wilson, and S. Barras. 2006a. Green and blue lasers are ineffective for dispersing deer at night. Wildlife Society Bulletin 34:371-374.

VerCauteren, K. C., J. A. Shivik, and M. J. Lavelle. 2006b. Efficacy of an animal-activated frightening device on urban elk and mule deer. Wildlife Society Bulletin 33:1282-1287.

Wagner, K. K., and D. L. Nolte. 2001. Comparison of active ingredients and delivery systems in deer repellents. Wildlife Society Bulletin 29:322330.

Zeger, S. L., and K. Liang. 1986. Longitudinal data analysis for discrete and continuous outcomes. Biometrics 42:121-130.

Associate Editor: Mason. 